\title{
Synthesis of Naphthalene based Quinoxaline derivatives using surfactant and their biological applications as Drugs
}

\section{GOVINDARAJ CHINNASAMY ${ }^{1 *}$, KULLAGOUNDER SUBRAMANI ${ }^{2}$, VENKATESAN SRINIVASAN ${ }^{3}$}

\author{
${ }^{1}$ Research Scholar, Department of Chemistry, Manonmaniam Sundaranar University, \\ Tirunelveli, Tamilnadu, India. \\ ${ }^{2}$ Department of Chemistry, Islamiah College, Vaniyambadi, Tamilnadu, 635752, India. \\ ${ }^{3}$ Department of Chemistry, Adhiyamaan College of Engineering, Hosur, \\ Tamilnadu, 635109, India. \\ ${ }^{*}$ Corresponding author E-mail: gshchemistry@gmail.com
}

http://dx.doi.org/10.13005/ojc/330430

(Received: August 15, 2016; Accepted: December 12, 2016)

\begin{abstract}
One pot synthesis of Naphtaleno-4, 6-(2, 4-quinoxaline) derivatives were achieved using direct coupling reaction by retaining 2,3-diaminonaphthalene as common with different forms of diketones viz., Benzil, 4, 4'-dimethyl benzil and 4, 4'-difluoro benzil. The synthesis was carried out using CTAB and polymer supported sulphanilic acid, independently. The use of 4, 4'-difluoro benzil was found to be better than 4, 4'-dimethyl benzils, in terms of the \% yield and the time consumption. Results confirmed that the use of CTAB was superior to the sulphanilic acid in the majority of aspects. Quinoxaline derivatives, so obtained, were independently used for the biological study to determine their efficiency in mice for anxiolytic, sedative and hypnotic activity. It was learned from the results that the Naphtaleno-4, 6-(2, 4-quinoxaline) derivatives were far better than their standard Diazepam in sedative and hypnotic activity. However, the efficiency was comparatively lesser than Diazepam in anxiolytic activity. In most cases, Fluoro substituted Diazepine show deviation in activity. The results of locomotor activity suggest the appreciable alertness of the mice when exposed to naphthalene based quinoxaline drugs.
\end{abstract}

Keywords: Quinoxaline derivatives, CTAB, sulphanilic acid, anxiolytic, sedative, hypnotic.

\section{INTRODUCTION}

Quinoxalines have been extensively synthesized for their ability to antibiotic, antiviral, anti-carcinogenic and antibacterial and the like medicinal properties. Their derivatives are found to suit a broad spectrum of biological and medicinal interest. Their applications do not end with the disease curing drugs, but also extends as industrially useful elements like dyes and electro-luminescent materials. 
Research has been currently made to increase the yield, efficiency and to decrease the timing, cost of these highly wanted drugs. Several promoters, catalysts and surfactants have been employed in this regard. The most common precursor viz., o-Phenyline diamine and their substituted derivatives are known. In general, quinoxalines are synthesized by the simple condensation of Naphthalene 2, 3-diamines with benzil compounds by the formation of $\mathrm{C}-\mathrm{C}$ and carbon-heteroatom ${ }^{1}$ using CTAB as the surfactant. This is one of the well known ways for developing green synthetic routes. 1, 2-diketones appear frequently as substituted by condensation of aryl-1, 2-diamines with benzil compounds.

The preparation of Quinoxaline by the reaction of benzils and their derivatives with Naphthalene based diamines uses surfactant property and hence, CTAB was considered as the surfactant medium for the reaction ${ }^{2}$. In order to find other competing catalyst that may be better than $\mathrm{CTAB}$, in this paper, we compared the efficiency of the same synthesis with that of the polymer supported sulphanilic acid ${ }^{3}$. The resulting quinoxaline products were verified for their biological applications such as anxiolytic, sedative and hypnotic activities on mice.

\section{MATERIALS AND EXPERIMENTAL METHODS}

\section{Chemistry}

Melting point of the resulting products were determined using a capillary in a melting point apparatus (Toshiba) and are noted as such. The FTIR Spectra were recorded on a Perkin Elmer Spectrum1 FT-IR instrument with the resolution of $1.0 \mathrm{~cm}^{-1}$ using the $\mathrm{KBr}$ disc in the range of $4000-400 \mathrm{~cm}^{-1}$. The PMR and CMR spectra were measured on a Bruker Advance III instrument (600 and $150 \mathrm{MHz}$, respectively) using a solvent signal as the reference. The units of Chemical shifts $(\delta)$ are given in ppm and coupling constants $(\mathrm{J})$ in $\mathrm{Hz}$. Assignments of signals in CMR spectra were made on the basis of the HMQC experiments.

Both 2,3-diaminonapthalene (99.9\%), 1,2-diketones (99.8\%) were obtained from SigmaAldrich, India and were used as such without further purification. 1,2-diketone was used in three different forms namely, benzil, 4,4'-dimethylbenzil and 4,4'diflurobenzil for the purpose of finding the substituent effect. CTAB was used as the cationic surfactant. A mixture of $1 \mathrm{M} \mathrm{HCl}$ and Ethanol-spirit was used as the solvent. After the reaction completion (which was completely monitored by TLC), the synthesized product was precipitated by using Ethanol. Surfactant (CTAB) was left in the solvent without further actions.

\section{Procedure for the synthesis of derivatives}

In a $100 \mathrm{ml}$ beaker, $2 \mathrm{mmol}$ of Benzil, 2 $\mathrm{mmol}$ of CTAB were added to $10 \mathrm{ml}$ Ethanol and placed on a magnetic stirrer cum temperature bath at stirring speed of $750 \mathrm{rpm}$ at $35^{\circ} \mathrm{C}$, a little higher than room temperature. A mixture of $10 \mathrm{ml}$ of 2, 3-diaminonapthalene dissolved in $1 \mathrm{M} \mathrm{HCl}$ was added in-situ to this reaction mixture drop by drop. A pale brown coloured precipitate was obtained after 10 minutes. The precipitate was filtered using Whatmann 40 filter paper and subsequently dried under shadow. The precipitate was re-crystallized with ethanol. This re-crystallized yield was used as a source for further TLC and HPLC chromatographic studies followed by spectroscopic characterization. The structure of the resulting compound was as shown in the Figure 1.

\section{Procedure for the synthesis of 2, 3-diphenyl benzo [g] quinoxaline}

In a $100 \mathrm{ml}$ beaker, $2 \mathrm{mmol}$ of 1,2-diphenylethane-benzil, $2 \mathrm{mmol}$ of CTAB were added to $10 \mathrm{ml}$ Ethanol and placed on magnetic stirrer, added with 2 $\mathrm{mmol}$ of 2,3-diaminonaphthalene in $10 \mathrm{ml} 1 \mathrm{M} \mathrm{HCl}$, in-situ to this reaction mixture, drop by drop. The precipitate was re-crystallized with ethanol.

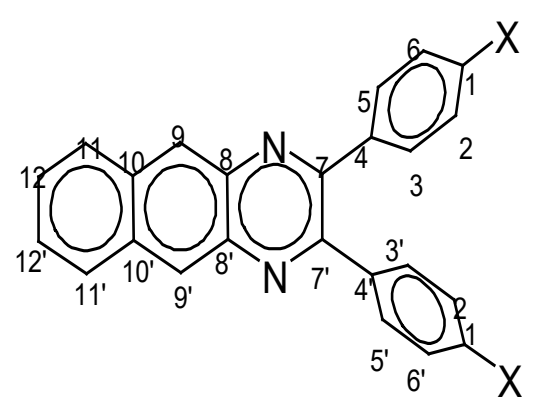

Fig. 1: Structural formula of 2,3Diphenylbenzo(g)quinoxaline $[\mathrm{X}=\mathrm{H}$ or $-\mathrm{M}$ or $+\mathrm{M}$ group] 


\section{Characterization of 2, 3-diphenyl benzo [ $g$ ] quinoxaline}

Yield $=97 \%$ : Pale Brown coloured crystals: m.p. $=99^{\circ} \mathrm{C} ; \mathrm{FTIR}$ : Heterocyclic $-\mathrm{C}=\mathrm{N} \&-\mathrm{C}=\mathrm{C}-$ str. $=1595.13 \mathrm{~cm}^{-1}$, aromatic $-\mathrm{CH}$ str. $=3061.03 \mathrm{~cm}^{-1}$, aromatic $-\mathrm{C}=\mathrm{C}$ - str. $=1666.50 \mathrm{~cm}^{-1}$, aromatic $-\mathrm{C}-\mathrm{C}-$ str. $=1517.98 \mathrm{~cm}^{-1}$, aromatic $-\mathrm{C}-\mathrm{N}-\mathrm{str} .=1325.10$ $\mathrm{cm}^{-1} ; \mathrm{H}^{1} \mathrm{NMR}:(400 \mathrm{MHz}, \mathrm{DMSO}): \delta=7.946-7.925$ $(\mathrm{J}=1.9622)$ (t, 2H, arom.); $\delta=7.829-7.791(\mathrm{~J}=$ $1.000)(\mathrm{t}, 2 \mathrm{H}$, arom. $) ; \delta=7.660-7.621(\mathrm{~J}=2.0311)(\mathrm{t}$, $4 \mathrm{H}$, arom.); C ${ }^{13} \mathrm{NMR}$ : (400 MHz, DMSO) $\delta=194.79$, $135.50,132.25,129.66,129.56,129.48,128.39$, $128.01,127.11,40.18,39.97,39.76,39.55,39.34$, 39.14, 38.93 ppm.

\section{Procedure for the synthesis of 2, 3-bis(4- methylphenyl)benzo[g]quinoxaline}

In a $100 \mathrm{ml}$ beaker, $2 \mathrm{mmol}$ of 4,4'dimethylbenzil, $2 \mathrm{mmol}$ of CTAB were added to 10 $\mathrm{ml}$ Ethanol and placed on magnetic stirrer, added with $2 \mathrm{mmol}$ of 2,3-diaminoNapthalene in $10 \mathrm{ml} 1 \mathrm{M}$ $\mathrm{HCl}$, in-situ to this reaction mixture, drop by drop. The precipitate was re-crystallized with Ethanol.

\section{Characterization of 2, 3-bis(4-methylphenyl) benzo[g]quinoxaline}

Yield $=95 \%$ : Pale Brown coloured crystals: M.P. $=107^{\circ} \mathrm{C} ; \mathrm{FTIR}$ : Heterocyclic $-\mathrm{C}=\mathrm{N}$ str. \& $-\mathrm{C}=\mathrm{C}-$ str. $=1595.13 \mathrm{~cm}^{-1},-\mathrm{C}-\mathrm{H}-\mathrm{str}$. in $\mathrm{CH}_{3}=2922.16 \mathrm{~cm}^{-1}$, aromatic C-H str. $=3047.53 \mathrm{~cm}^{-1}$, aromatic $-\mathrm{C}-\mathrm{C}$ - str. $=1429.25 \mathrm{~cm}^{-1}$, aromatic $-\mathrm{C}=\mathrm{C}-\mathrm{str} .=1662.64 \mathrm{~cm}^{-1}$, aromatic $-\mathrm{C}-\mathrm{N}-\mathrm{str} .=1313.52 \mathrm{~cm}^{-1}$, , in-plane bending of $-\mathrm{C}-\mathrm{H}$ - in $\mathrm{CH}_{3}=1037.70 \mathrm{~cm}^{-1}$, out of plane bending of $-\mathrm{C}-\mathrm{H}$ - in $\mathrm{CH}_{3}=736.81 \mathrm{~cm}^{-1} ; \mathrm{H}^{1} \mathrm{NMR}:(400 \mathrm{MHz}$, DMSO) $\delta=7.809-7.788$ ( $\mathrm{J}=2.000)$ (d, 8H, arom.); $\delta=7.441-7.420(\mathrm{~J}=2.0416)(\mathrm{d}, 6 \mathrm{H}$, arom. $) ; \delta$ $=2.414\left(\mathrm{~s}, 3 \mathrm{H}\right.$, in $\left.-\mathrm{CH}_{3}\right) \mathrm{C}^{13} \mathrm{NMR}:(400 \mathrm{MHz}, \mathrm{DMSO})$ $\delta=194.60,146.44,130.03,129.95,129.59,40.18$, $39.97,39.76,39.55,39.34,39.13,38.92,21.41$ ppm.

Procedure for the synthesis of 2, 3-bis(4fluorophenyl)benzo[g]quinoxaline

In a $100 \mathrm{ml}$ beaker, $2 \mathrm{mmol}$ of 4,4'difluorobenzil, $2 \mathrm{mmol}$ of CTAB were added to $10 \mathrm{ml}$ Ethanol and placed on magnetic stirrer, added with $2 \mathrm{mmol}$ of 2,3-diaminoNapthalene in $10 \mathrm{ml} 1 \mathrm{M}$ $\mathrm{HCl}$, in-situ to this reaction mixture, drop by drop. The precipitate was re-crystallized with Ethanol.
Characterization of 2, 3-bis(4-fluorophenyl) benzo[g]quinoxaline

Yield $=98 \%$ : Pale Brown coloured crystals. m. p. $=118^{\circ} \mathrm{C}$; FTIR: Heterocyclic $-\mathrm{C}=\mathrm{N} \&-\mathrm{C}=\mathrm{C}-$ str. $=1597.06 \mathrm{~cm}^{-1}$, aromatic $-\mathrm{C}-\mathrm{H}$ str. $=3074.53 \mathrm{~cm}^{-1}$, aromatic $-\mathrm{C}=\mathrm{C}$ - str. $=1666.50 \mathrm{~cm}^{-1}$, aromatic $-\mathrm{C}-\mathrm{C}$ str. $=1506.41 \mathrm{~cm}^{-1}$, aromatic $-\mathrm{C}-\mathrm{N}$ str. $=1317.38$ $\mathrm{cm}^{-1}, \mathrm{C}-\mathrm{F}$ bond $=1101.35 \mathrm{~cm}^{-1} ; \mathrm{H}^{-1} \mathrm{NMR}(400 \mathrm{MHz}$, DMSO) $\delta=8.072-8.021(\mathrm{~J}=2.00)(\mathrm{m}, 8 \mathrm{H}$, arom.); $\delta=7.497-7.439 \quad(\mathrm{~J}=2.0417)(\mathrm{m}, 6 \mathrm{H}$, arom. $) ;$ $\mathrm{C}^{13} \mathrm{NMR}(400 \mathrm{MHz}$, DMSO) $\delta=192.60,167.51$, $164.97,133.06,132.96,128.99,128.97,116.86$, $116.64,40.11,39.91,39.70,39.49,39.28,39.07$, 38.86 .

\section{Pharmacology}

\section{Animal subject used}

Swiss albino mice of male gender (21-24 g) were used throughout the study. They were provided normal pellet diet and drinking water ad libitum and were exposed to $12 \mathrm{~h}$ sunlight and $12 \mathrm{~h}$ dark cycle. The animals were made physiologically responsive to the laboratory conditions prior to the experiments. Animals' care was taken as per guidelines of the Committee for the Purpose of Control and Supervision of Experiments on Animals (CPCSEA), Environment and Forests Ministry, India.

\section{Drugs used}

Diazepam hydrochloride (Ranbaxy Laboratories, Gurgaon, India) was procured and used as a standard drug and it was diluted with saline water to the needed strength prior to the use. The test compounds were suspended in $0.3 \% \mathrm{w} / \mathrm{v}$ of sodium carboxymethyl cellulose (CMC) and were administered through oral gavage.

\section{Acute Toxicity Studies}

Acute Oral Toxicity (AOT 423) guideline was followed for the acute toxicity studies of the synthesized compounds. Briefly, overnight fasted animals were treated with various concentrations of the compounds to be tested $(5,50,300$ and 2000 $\mathrm{mg} / \mathrm{kg}$, bw) by oral route. The observation of animals for any behavioral changes or mortality for first $24 \mathrm{~h}$ was done. The animals were maintained for another 14 days to check the abnormal changes and mortality. Based on the results, the dose was fixed for pharmacological studies. 


\section{Anxiolytic activity Elevated Plus Maze (EPM) Test}

To assess the anti-anxiety activity of test compounds, elevated plus maze (EPM) was used 4 . Two open arms $(16 \times 5 \mathrm{~cm})$ and two closed arms $(16 \times 5 \times 12 \mathrm{~cm})$ having an open roof, with the plus-maze elevated $(25 \mathrm{~cm})$ from the floor was the set up. Each mouse was individually placed at the centre of the EPM with its head facing exactly the open arms. This experiment lasts 5 minutes, during which behavior of the mouse was recorded as: (a) the number of entries of drug into the open arms, (b) mean time spent by the mouse in the open arms (mean time or average time = total time spent in open arms/number of entries in arms).

\section{Procedure}

Animals were divided in to 11 groups, each 6 in a group. The Group I served as control served with vehicle, Group II served as standard served with diazepam at the dose of $0.5 \mathrm{mg} / \mathrm{kg}$. Group III - XI the animals were treated with the compounds to be tested at the dose of $(5 \mathrm{mg} / \mathrm{kg}$, bw, p.o). The compounds were administered through oral way using a tuberculin syringe fitted with oral canula. The drug administration schedule was adjusted so that each mouse was having its turn on the EPM apparatus 45 minutes after the administration of the dose. During the complete experiment, all the animals were allowed to socialize. Every care was taken to make sure that no external stimuli, other than the height of plus-maze could invoke anxiety in the animals. The parameters noted is (a). Time spent in open arm and (b). Number of arm entries to assess the anxiolytic activity.

\section{Sedative and Hypnotic activity Hole - Board Test}

In order to examine the sedative and hypnotic activity of the synthesized compounds, Hole-Board Test was performed. The Hole-board apparatus is set to comprise a grey Perspex panel $(40 \times 40 \mathrm{~cm}, 2.2 \mathrm{~cm}$ thick) with 16 equidistant holes (diameter of $3 \mathrm{~cm}$ ) in the floor. Photocells below the surface of the holes have given way for the measure of the number of head dips. The board was placed $15 \mathrm{~cm}$ above the table and it was divided with black water-resistant marker into 9 squares of $10 \times 10 \mathrm{~cm}$. 30 minutes after the introduction of the test drug; each mouse was separately placed in the centre of the board. During these 5 minutes of test period, number of head dips was observed.

\section{Procedure}

Animals were broadly divided in to eleven groups, each 6 in a group. The Group I served as control served with the vehicle, Group II served as standard served with diazepam drug at the dose of $3 \mathrm{mg} / \mathrm{kg}$. Group III - XI the animals were treated with the test compounds at the dose of ( $5 \mathrm{mg} / \mathrm{kg}$, bw, p.o). The compounds to be tested were introduced orally using a tuberculin syringe fitted with oral canula. After 45 minutes of oral administration of the test compounds, the animals were placed in to the center of the perforated board and noted for the period of 5 minutes and the number of head exploration was counted in order to find out the sedative and hypnotic activity.

\section{Locomotor activity}

To evaluate the spontaneous locomotor activity of the synthesized compounds, actophotometer was used. Actophotometer (Popular Traders, Ambala, India) was utilized for the present study. Mice were placed separately in activity cage for 5 minutes test period, 45 minutes after the introduction of test drugs. Locomotor activity was noted in terms of the activity scores.

\section{Procedure}

Animals were divided in to 11 groups, each group consists of 6 animals. The Group I served as control served with vehicle, Group II animals served as standard which receives diazepam at the dose of $3 \mathrm{mg} / \mathrm{kg}$, through intra-peritoneal route. Group III - XI the animals were treated with the test compounds at the dose of (5 mg/kg, bw, p.o). The test compounds were administered orally by the use of a tuberculin syringe fitted with oral canula. After 45 minutes of oral introduction of the various fractions the animals were placed in to the actophotometer. Movement of the animal is recorded by the light beams present inside the actophotometer for the evaluation of the locomotor activity.

\section{RESULTS AND DISCUSSION}

\section{Synthesis and Characterizations}

Condensation of 2, 3-diaminonapthalene with benzil was employed as the key reaction. The 
effect of para substituent present on was verified by varying different types of groups (such as electron donating and electron withdrawing) and the corresponding results are mentioned in table 1. From the results, the electron withdrawing substituent such as -Fluro, yield (Scheme III) was better than the electron donating groups such as -Methyl, (Scheme II).

The method for the synthesis of 2-substitute benzothiazoles from the reaction of 2-aminothiophenol with aldehyde catalysed by CTAB in water ${ }^{5}$ was followed. One step synthesis of mesoporous material was achieved by adopting the double templates consisting of the conventional cation hyamine surfactant $\mathrm{CTAB}^{6}$.

\section{Acute Toxicity Studies}

Oral toxicity study for the test compounds were determined as per AOT 423 guidelines. Two out of three animals were died in the group of animals treated with $300 \mathrm{mg} / \mathrm{kg}$, bw, hence the preceding dose was considered as LD50 dose. A dilute quantity of drug i.e., one tenth of the dose $(5 \mathrm{mg} / \mathrm{kg}$, bw) was used for further studies.

\section{Anxiolytic activity}

Synthesis of aromatic condensed naphthoxazinone derivatives has received considerable attention because of their broad spectrum of biological properties ${ }^{7}$. Only compounds such as Quinoxaline diones and their derivatives effect by stimulating low index of open arm avoidance in mouse in an EPM test model of Anxiolytic activity. Compounds such as Sulphanilamide based quinoxaline and their derivatives show anxiolytic effect in mouse that was superior to the effect product by diazepam while the compound such as quinoxaline diones show anxiolytic effect comparable to diazepam ${ }^{8}$. Some simple 2,3-quinoxaline diones containing $+\mathrm{I}$ and $-\mathrm{I}$ groups and two quinoxalinone only one carbonyl functional group has synthesized and screened for neuro-pharmacological activity in mice and rats $^{9}$. Only the $\mathrm{c}$

hloro- functional group at position 6 and $\mathrm{N}$, $\mathrm{N}$-dibenzylsulphonamido group are essential for neuro-production against the induced seizers, in addition to the observed good activity of the dibenzylsulfonamido quinoxaline diones.

The time spent by the animals in the open

Table 1: Reaction schemes<smiles>Nc1cc2ccccc2cc1N</smiles><smiles>Nc1cc2ccccc2cc1N</smiles><smiles>Nc1cc2ccccc2cc1N</smiles>

Benzil Qunioxaline Scheme<smiles>c1ccc(-c2nc3cc4ccccc4cc3nc2-c2ccccc2)cc1</smiles>

BEN<smiles>Cc1ccc(-c2nc3cc4ccccc4cc3nc2-c2ccc(C)cc2)cc1</smiles>

BEN-Me

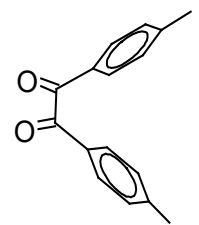

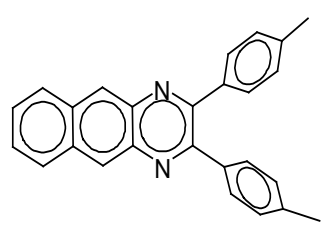


arms treated with standard drug diazepam and test compounds was significantly increased when compared to the control group which was treated with the same volume of vehicle. Among the test compounds, all the three substituted quinoxaline series showed significant anxiolytic activity, which shows mild to moderate activity. These compounds show a little difference when compared to the standard drug which indicates that the compounds are equipotent anxiolytic to the standard diazepam. The results are depicted in the figures $2 \mathrm{a}$ and $2 \mathrm{~b}$.

It can be observed from the Figure $2 \mathrm{a}$ that the time spent in open arm is increased nearer to the standard diazepam. Using the Figure $2 b$, the gradual increase in number of arm entries based on the potency of the individual test compounds, can be witnessed. It should be noted that the increase in open arm entry data is the most important index of anxiolytic activity. Time spent on the central platform appears to be relevant to decision making process and risk assessment process, further, the total arm entries is the direct measure reflecting the changes in anxiety. The enhanced activity of the quinoxaline drug and its derivatives is expected to be due to the binding site of the ion channel receptor present in the CNS. This in turn, would stimulate the binding of GABA $_{A}$ subunit with the GABA receptor, which would produce the prolongation of opening of the channels of chloride ion. The prolonged opening leads to mild hyper polarization which may be responsible for

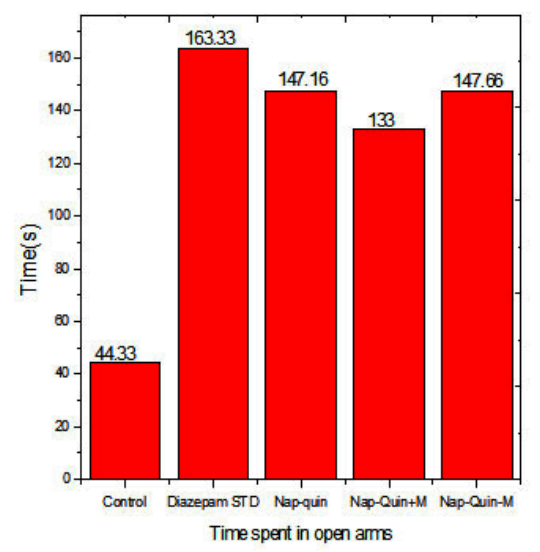

the noted anxiolytic activity of the test compounds. Quinoxalines act not just by substituting for GABA ${ }_{A}$, which bind at the á-subunit, but also increase the number of channel opening events, which leads to an increase in conductance of Chloride ion and also inhibition of the action potential ${ }^{10}$.

\section{Sedative and Hypnotic activity}

The hole-board test used to assess the sedative and hypnotic potential of the test compounds. This test confirmed the CNS calming nature of the test compounds. The results are shown in the Figure 3. The number of hole explore was counted for the period of 5 minutes and the results revealed that the control animal was active whereas the head exploration has been largely reduced in the animals treated with the standard diazepam drug at the dose of $4 \mathrm{mg} / \mathrm{kg}$. The test compounds possess various degree of hole exploration values. Diazepam is the CNS depressant used in the management of sleep disorders such as insomnia; these drugs have a binding site on GABA receptor type-A ionophore complex $\left(G_{A B A_{A}}\right)$. The drug decreases activity, moderates excitement and calms the nerve recipient. GABAergic pathway, since its transmission can produce profound sleeping in mice. The ordinary inhibitory action of GABA consists in the opening of chloride channels to allow hyperpolarizing the membrane, leading to CNS depression and results in sedative and hypnotic activity. Glutamate and GABA are quantitatively the most representative excitatory

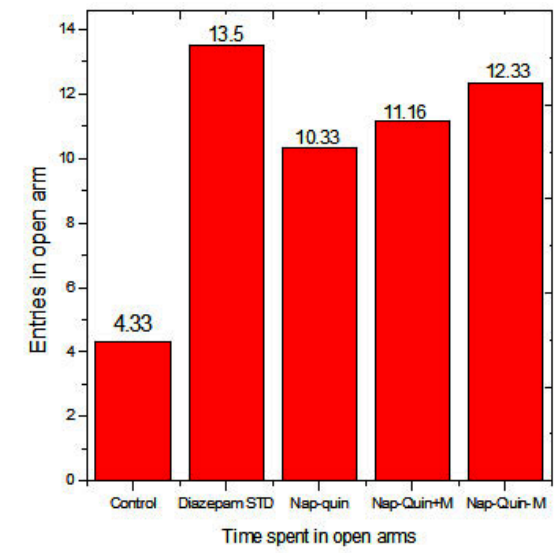

Fig. 2a: Time spent in open arms; 2b.Entries in open arm [Standard Diazepam 0.5mg/kg]

[Values are expressed as Mean \pm SEM; a $P<0.001$, ${ }^{b} \mathrm{P}<0.01$ vs Control group; ${ }^{\mathrm{C}} \mathrm{P}<0.001,{ }^{\mathrm{d}} \mathrm{P}<0.01$, eP $<0.05$ vs Std group; Data were analyzed by using One way ANOVA followed by Tukey Kramer Multiple comparison Test.] 


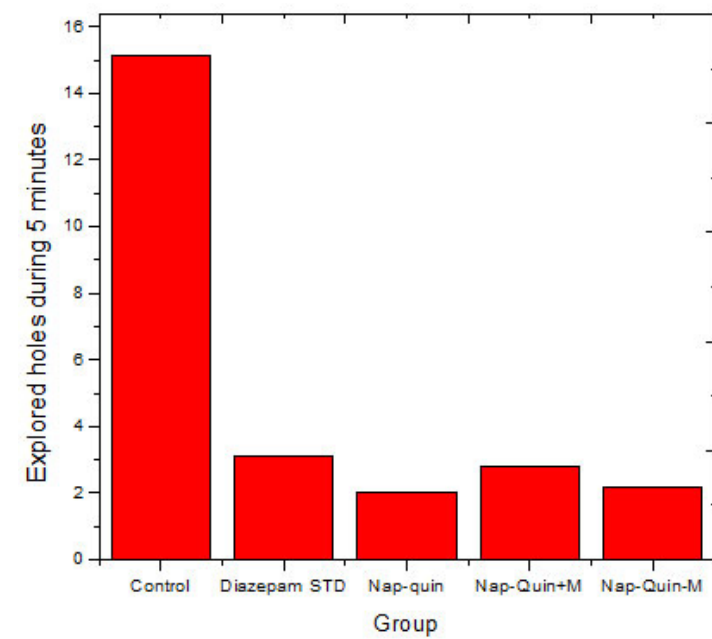

Fig. 3: Sedative and Hypnotic activity [STD Diazepam $3 \mathrm{mg} / \mathrm{kg}]$

[Values are expressed as Mean \pm SEM; ${ }^{\mathrm{a} P}<0.001,{ }^{\mathrm{b}} \mathrm{P}<0.01$ vs Control group; ${ }^{\mathrm{c}} \mathrm{P}<0.001$, ${ }^{d} \mathrm{P}<0.01$ vs Standard group; Data were analyzed by using One way ANOVA followed by Tukey Kramer Multiple comparison Test.]

and inhibitory neurotransmitters, respectively, in the mammalian brain. Thus, receptors for these two neurotransmitters are regarded as usual and essential targets for psychotropic drugs. The activity of the compound to be tested may be due to binding with these receptors.

\section{Locomotor activity}

The mean score in locomotor activity, before and after the treatment were measured and are shown in the Figure 4. There are notable difference observed in the mean score before treatment with standard and the test compounds. After the standard/test drug treatment, the mean score for the diazepam treated group and the test Quinoxaline derivatives treated, together appear lesser active, when compared to the control group. But the test compounds were observed to show worthier statistics when compared to the standard drug. The results revealed the significant reduction in locomotor activity by the quinoxaline based derivatives. Locomotor activity is believed as an index of alertness and a reduction in that is an indicative of sedative activity. GABA is the important inhibitory neurotransmitter in the CNS and different anxiolytic, muscle relaxant and sedative-

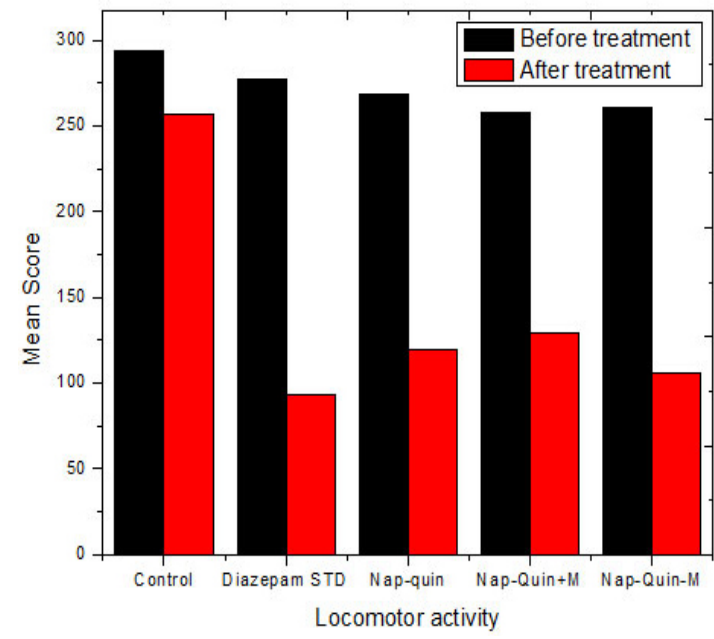

Fig. 4: Locomotor activity [STD (Diazepam $3 \mathrm{mg} / \mathrm{kg})$ ]

[Values are expressed as Mean \pm SEM; ${ }^{\text {aP }}<0.001,{ }^{\mathrm{b}} \mathrm{P}<0.05$ vs Control group; ${ }^{\mathrm{C}} \mathrm{P}<0.001 \mathrm{vs}$ Standard group; Data were analyzed by using One way ANOVA followed by Tukey Kramer Multiple comparison Test.]

hypnotic drugs are expected to exhibit their action through GABA. Therefore, it is possible that the test compounds may act by direct activation of GABA receptors by the test compounds. The increase in efficiency of the natural brain chemical, GABA $A_{A}$, by the quinoxaline based derivative is achieved along with the decrease in excitability of neurons.

\section{CONCLUSIONS}

Naphthalene based Quinoxalines were successfully synthesized with greater yield (96\%) and shorter duration (5 minutes) using CTAB as the surfactant. The synthesis in the absence of cationic surfactant resulted in poor yield and time consuming ( $35 \%$ and $90 \mathrm{~min}$ ). The solubility of this compound in ethanol, suggests that this product can be used as a challenging drug for the pathogens. The synthesis of naphthalene-quinoxaline by this method produced no harmful emissions. These provide a very good option for non-toxic drug possessing anxiolytic, sedative and hypnotic properties. When compared with benzodiazepine drugs, these naphthalene based quinoxaline drugs shows a little lower effective as an anxiolytic drug and better effect as a sedative and hypnotic. 


\section{ACKNOWLEDGEMENTS}

Authors are grateful to their respective institutions, where they are working, and
Manonmaniam Sundaranar University, Tirunelveli, for extending permission, support and infrastructure.

\section{REFERENCES}

1. Chen, J.X.;Wu, H.Y., Jin, C.; Zhang X.X.; Xie, Y.Y.; Su, W.K.; Green Chem., 2006, 8, 330.

2. Agarwal Singh, M.; Mcpherson, G.; John, V.; Bose, A.; Colloids Surf. A, 2006, 281, 246.

3. Umesh, P.Tarpada.; Bhautik, B.Thummar.; Dipak, K.Raval.; Arabian Journal of Chemistry, 2013, http://dx.doi.org/10.1016/j. arabjc.2013.11.021.

4. Patel, M.; Mchugh, J. Jr. R.; Cordova.C.; Labe, R.M.; Erickson, V.S.; Trainer, G.L.; Ko, S.S.; Bioorganic Med. Chem. Lett., 1999, 9, 3221.

5. Xiao-Liang Yang, Chan-mci Xu; Shao-Miao Lin; Jiu-Xi Chen, Jin-Chang Zing Hua-Yue Wu and Wei-keSu., J.Brazilian Chemical Society, 2010, 21, 37-42.

6. Jun Hu, Feng Gao, Yazhuo Shang Chengjun Peng, Honglailu, Ying $\mathrm{Hu}$, Microporous and
Mesoporous materials, 2011, 142, 268-275.

7. Olayiwola, G.; Obafemi, C.A.; Taiwo, F.O.; African Journal of Biotechnology, 2007, 6(6), 777-786.

8. Obafemi, C.A.; Akinpeter, D.A.; Synthesis and antimicrobial activity of some $2(1 \mathrm{H})$ quinoxailnone-6-Sulphnyl derivatives of Phosphorous Sulphur, Silicon Relat. Elem. 2005, 180, 1795-1807.

9. Dimmock, J.R.; Baker, G.B., Anticonvulsant activities of 4-Bromobenzaldehyde Semicarbazone, Epilepsia, 1994, 35,648655.

10. Brambika, P.; Perez, J.; Scheltini and Soures, J.C.; Molecular Psychiatry, 2003, 8(8), 721737. 